\title{
Nasopharyngeal Necrosis After Chronic Opioid (Oxycodone/Acetaminophen) Insufflation
}

\author{
Christopher D. Rosenbaum • Katherine L. Boyle • \\ Edward W. Boyer
}

Published online: 14 March 2012

(C) American College of Medical Toxicology 2012

\begin{abstract}
Nasopharyngeal necrosis resulting from narcotic insufflation is a recognized phenomenon, but cocaine use is more commonly associated with this pathology than opioid abuse. Physical exam findings associated with severe tissue destruction are not routinely seen on physical examination or available in the medical literature. We present a case of chronic oxycodone/ acetaminophen insufflation and images of a defect in the soft palate.
\end{abstract}

Keywords Opioid · Oxycodone · Percocet · Insufflation · Drug abuse

Data have been previously presented at a meeting or in an abstract form. This study has been submitted as an abstract to NACCT 2012 in Las Vegas.

C. D. Rosenbaum $(\bowtie) \cdot$ E. W. Boyer

Department of Emergency Medicine, Division of Medical

Toxicology, University of Massachusetts Medical Center,

55 Lake Avenue North, LA-216,

Worcester, MA 01655, USA

e-mail: crosen5@gmail.com

K. L. Boyle

Department of Emergency Medicine,

University of Massachusetts Medical Center,

Worcester, MA, USA

\section{Clinical Narrative}

A 26-year-old female presented to the Emergency Department (ED), with stable vital signs, complaining of a headache. She stated that her primary care doctor, working in concert with an otolaryngologist, instructed her to return to the ED any time she had a significant headache. Her past medical history was significant only for crushing and insufflating Percocet ${ }^{\circledR}$ tablets for many years. She states that she has been sober for almost a year and denies taking any prescription or illicit drugs during that time. She denies insufflating any other medications or illicit drugs besides Percocet ${ }^{\circledR}$. On physical exam, she has hypernasal speech (i.e., cleft palate-like misarticulations), no visible external facial deformities, and no skin changes. Visual inspection of her oropharynx can be seen in the attached images. She denies any complaints other than a mild general headache.

The attached images demonstrate soft palate necrosis, with no appreciable damage to the hard palate. Her soft palate destruction was a continuation of the cartilaginous destruction evidenced by her obliterated nasal septum (Figs. 1 and 2). Despite her young age, this patient had a significant opioid addiction, and her only route of administration was insufflation over a 10 -year time period. Due to an increased risk of infection (resulting from loss of facial structures), the patient was started 


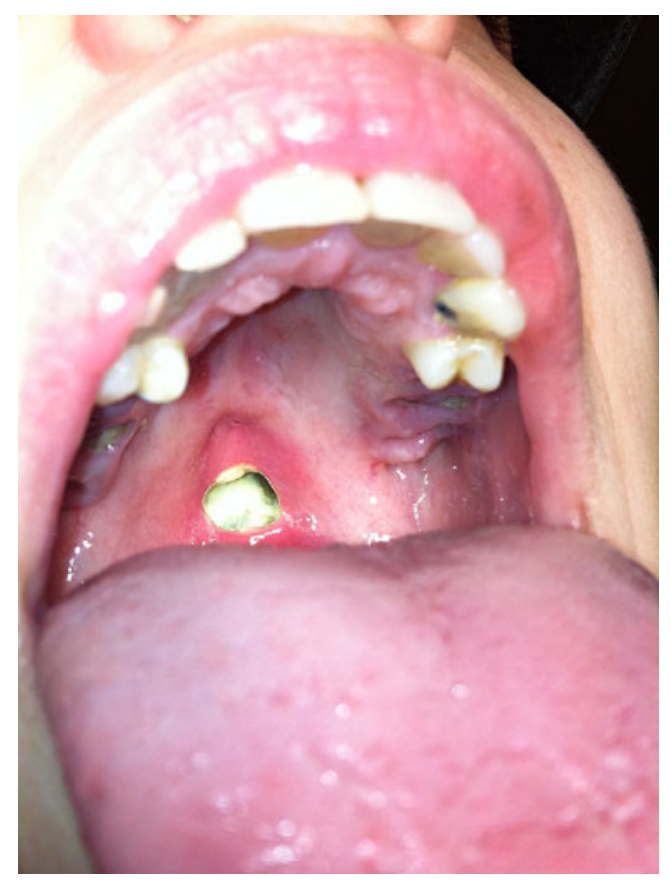

Fig. 1 Soft palate necrosis revealed during visual inspection of oropharynx. Image courtesy of Chris Rosenbaum

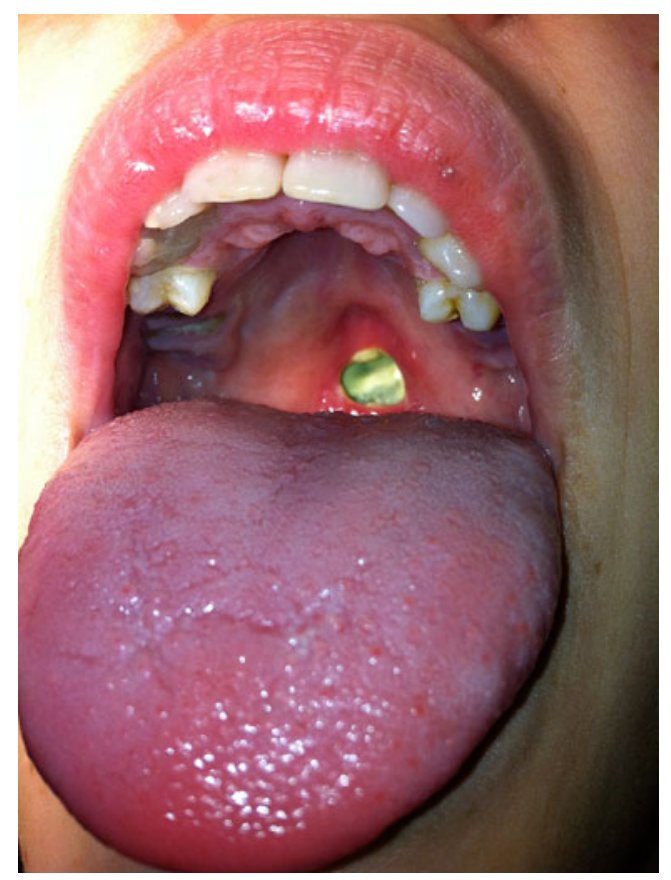

Fig. 2 The patient's soft palate destruction was a continuation of the cartilaginous destruction evidenced by her obliterated nasal septum. Image courtesy of Chris Rosenbaum on oral clindamycin and instructed to follow-up with outpatient otolaryngology consultation. Per the patient, there were plans for her to have a corrective surgery in the near future. This patient gave consent for her images to be used for publication and education.

Without a patient's specific description of drug diversion and insufflation, it is possible to miss the physical exam findings of nasal septum destruction or soft palate necrosis. Performing a careful physical exam of the nasal turbinates and the oropharynx may help the treating physician to better assess the patient's risk factors for infection. This patient had hypernasal speech, no visible nasal septum, and a defect in her soft palate. Treating physicians should be aware of the risk for infection, need for possible antibiotics and neuroimaging, and be in contact with otolaryngology or corrective surgical specialty.

Nasopharyngeal necrosis resulting from narcotic insufflation is a recognized phenomenon, but cocaine use is more commonly associated with this pathology than opioid abuse [1-6]. Physical exam findings associated with severe tissue destruction are not routinely seen on physical examination or available in the medical literature.

Conflicts of Interest None of the authors have any conflicts of interest.

\section{References}

1. Messinger E (1962) Narcotic septal perforations due to drug addiction. JAMA 179:964-965

2. Goodger NM, Wang J, Pogrel MA (2005) Palatal and nasal necrosis resulting from cocaine misuse. Br Dent J 198(6):333-334

3. Greene D (2005) Total necrosis of the intranasal structures and soft palate as a result of nasal inhalation of crushed OxyContin. Ear Nose Throat J 84(8):512, 514, 516

4. Birchenough SA, Borowitz K, Lin KY (2007) Complete soft palate necrosis and velopharyngeal insufficiency resulting from intranasal inhalation of prescription narcotics and cocaine. J Craniofac Surg 18 (6):1482-1485

5. Silvestre FJ, Perez-Herbera A, Puente-Sandoval A, Bagan JV (2010) Hard palate perforation in cocaine abusers: a systematic review. Clin Oral Investig 14(6):621-628

6. Brusati R, Carota F, Mortini P, Chiapasco M, Biglioli F (2009) A peculiar case of midface reconstruction with four free flaps in a cocaine-addicted patient. J Plast Reconstr Aesthet Surg 62(2): e33-e40 